\title{
Effects of stress and mood on caffeine consumption in shift and non-shift workers
}

\author{
R. M. Malone ${ }^{1}$, K. Giles ${ }^{1}$, N. G. Maloney ${ }^{1}$, C. L. Fyfe ${ }^{1}$, A. Lorenzo-Arribas ${ }^{2}$, D. B. O’Connor ${ }^{3}$ \\ and A. M. Johnstone ${ }^{1}$ \\ ${ }^{1}$ Rowett Institute of Nutrition and Health, University of Aberdeen, Greenburn Road, Bucksburn, Aberdeen AB21 9SB, \\ ${ }^{2}$ Biomathematics and Statistics Scotland, University of Aberdeen, Aberdeen AB21 9SB and ${ }^{3}$ Institute of Psychological \\ Sciences, University of Leeds, Leeds, West Yorkshire LS2 9JT
}

Growing evidence suggests a direct link between stress and health, through autonomic and neuroendocrine responses as well as an indirect link through behavioural responses ${ }^{(1)}$. Behaviour such as increased energy-dense snack consumption has been observed in shift workers ${ }^{(2)}$. In general, increased caffeine consumption has been related to periods of work-stress ${ }^{(3)}$. Caffeine influences the constituents of the neuroendocrine system associated with psychophysiological stress responses ${ }^{(4)}$. The present study therefore aims to enhance knowledge of caffeine-stress interactions within the workplace.

Food Frequency Questionnaires provided habitual caffeine intake information from 413 healthy male and female volunteers from different workplaces including shift and non-shift workers. Perceived stress, depression and anxiety levels were measured using the DASS- $21^{(5)}$ self-reported questionnaire. Additionally, the 'Daily Hassles' Questionnaire ${ }^{(1)}$ measured frequency and severity of daily stressors yielding a greater detail of subjective stressful events. Ordinal regression models controlling for age, gender, BMI and shift pattern were used to determine the effect of a relationship between caffeine and stress and stress-related disorders (depression and anxiety). Cut-off points of Low (0-170 mg/d), Moderate (>170-300 mg/d) and High (>300 mg/d) caffeine intake were considered for the analysis.

Mean (SEM) caffeine intake was $161.7(6.8) \mathrm{mg}$ /day for non-shift workers and $182.7(11.5) \mathrm{mg} /$ day for shift workers which was non significant $(p=0 \cdot 111) ; 161.4(7.8) \mathrm{mg} /$ day for women and $176.0(9 \cdot 1)$ for men which was also non significant $(p=0 \cdot 223) ; 157 \cdot 2(7 \cdot 4)$ $\mathrm{mg}$ /day for those under 45 years and $184.8(9.7) \mathrm{mg}$ /day for those over 45 years which was significant $(p=0.023) ; 165.0(9.0) \mathrm{mg} / \mathrm{day}$ for those with a BMI of less than $25 \mathrm{~kg} / \mathrm{m}^{2}, 165.6(8.7) \mathrm{mg} /$ day for those in the overweight BMI category $\left(25-30 \mathrm{~kg} / \mathrm{m}^{2}\right)$ and 181.6 $(16.2) \mathrm{mg} /$ day for those in the obese BMI category (over $\left.30 \mathrm{~kg} / \mathrm{m}^{2}\right)$, also non significant $(p=0.629)$. The results from the ordinal regression showed statistically significant effects of stress $(p=0.004)$ and hassle severity $(p=0.024)$, marginal statistically significant effect of depression $(p=0.058)$, and non-significant effects of anxiety $(p=0.529)$ and hassle frequency $(p=0 \cdot 193)$.

In conclusion, there was a significant relationship between age and caffeine intake and stress level and caffeine intake although no significant effects of shift pattern. Additionally, hassle severity affected caffeine intake although there was no effect in relation to number of hassles.

The work is funded by the European Union Seventh Framework Programme (FP7/2007-2013) under grant agreement n 245009 for the 'NeuroFAST' grant.

1. O'Connor DB, Jones F, Conner M et al. (2008) Health Psychol 27(1), S20-31.

2. Scott C \& Johnstone AM (2012) Obes Facts 5, 277-287.

3. Conway TL, Vickers RR, Ward HW et al. (1981) J. Health Soc. Behav 22(2), 155-165.

4. Lane JD (1994) Psychosom Med, 56(3), 267-70.

5. Lovibond SH \& Lovibond PF (1995) In Manual for the Depression Anxiety Stress Scales, 2nd ed., Sydney: Psychology Foundation. 